\title{
Back2Work: A new model of early vocational rehabilitation for people with spinal cord injury
}

\section{Abstract}

Objective: The aim of this article is to describe the development of a novel evidencebased model of early intervention vocational rehabilitation (EIVR) for people with spinal cord injury (SCl).

Methods: An extensive literature review and background study guided the collaboration of experienced practitioners and researchers in developing and evaluating the innovative Back2Work Model of EIVR for people with SCl in Queensland, Australia. The program is undergoing longitudinal, mixed-methods evaluation to end 2023.

Results: The Model is central to the successful implementation of the EIVR program, delivered by Rehabilitation Counsellors in the Queensland Spinal Injuries Unit. 'Back2Work' includes a strong focus on maintaining and nurturing the pre-injury occupational bond between injured workers and employers, and aims to create a positive expectation for RTW and increase the rate and timeliness of RTW after SCI. Conclusions: The Back2Work program has become an integrated component of the multidisciplinary rehabilitation team, with positive early results in RTW outcomes and additional benefits in participants' sense of wellbeing and hope.

Keywords: vocational rehabilitation; return to work; spinal cord injury; model; employment 


\section{Why 'work', and why 'early'?}

Spinal cord injury (SCl) can have significant impacts on an individual's functional, psychosocial and financial situation. ${ }^{1-4}$ As well as the obvious and direct consequences of the injury there are enormous indirect consequences, including loss of productivity and employability. ${ }^{5,6}$ In particular, SCI has been shown to have substantial negative impacts on vocational pathways of those who sustain such injuries, ${ }^{7-10}$ including dramatic reduction in the rate of employment, significant delays in returning to work, increased likelihood of underemployment, reduced job retention and lowered job satisfaction. ${ }^{11-13}$ Return to paid employment is, however, often considered one of the most meaningful measures of rehabilitation success ${ }^{14,15}$ and strong associations have been reported between vocational outcomes and health and quality of life. ${ }^{16,17}$ To date, research has provided limited insights into ways to address or mitigate the risks to vocational participation and careers following $\mathrm{SCl}{ }^{18}$

The emerging evidence in $\mathrm{SCl}$ and other injury groups, such as acquired brain injury, suggests early intervention is vital to addressing some of the concerns and impacts highlighted in the $\mathrm{SCl}$ employment literature. Until recently, the concept of early intervention in the $\mathrm{SCI}$ injury group has been considered incongruous with favorable adjustment outcomes. Traditional approaches in SCI rehabilitation have been based on assumptions that extended periods of time are required to facilitate psychosocial adjustment, before considering return to work. ${ }^{7-10}$ Vocational intervention has therefore typically been delivered post-discharge through referral to disability employment services or via insurer-funded private rehabilitation providers. Early intervention vocational rehabilitation (EIVR) therefore refers to vocational services that commence prior to hospital discharge or during the initial rehabilitation phase. 
Research suggests that the recovery journey after major injury may be supported and enhanced through nurturing hope ${ }^{19,20}$ and encouraging motivation. ${ }^{8}$ Early consideration of vocational goals during rehabilitation may communicate that returning to work is not only possible, but likely. ${ }^{21}$ This may in turn enhance hope and motivation to persevere in the face of significant trauma such as SCI. ${ }^{8}$ Further, early contact between the injured worker and their employer may support the occupational bond or emotional connection to the person's pre-injury employment. Occupational bonds are conceptualised as the psychological bond between a person and their job, employer, workplace, co-workers, or job role. ${ }^{22}$ Maintenance of the occupational bond is a primary target of traditional vocational rehabilitation interventions to promote better return to work outcomes. ${ }^{22,23}$ For those who cannot return to the same role, EIVR can support their connection to their identity as a "worker", thus preserving return to work (RTW) motivation. ${ }^{22}$

There is an emerging body of research detailing the benefits of earlier vocational rehabilitation following major injuries, including acquired brain injury, ${ }^{24}$ burns, ${ }^{25}$ musculoskeletal injuries, ${ }^{26}$ and $\mathrm{SCl} .{ }^{21,27,28}$ From consumer perspectives, it has been noted that people feel willing and ready to discuss their vocational options and support needs soon after their injury, while still participating in hospital-based rehabilitation. ${ }^{10,29}$ These interventions can lead to enhanced outcomes across other domains of rehabilitation by motivating commitment to and hope for physical rehabilitation and psychosocial adjustment. 8,30 This growing body of EIVR literature prompted the coming together in 2015 of a group of practitioners and researchers concerned with the gap in vocational service provision for people with recently acquired SCI in Queensland, Australia. The cross-disciplinary group shared significant knowledge and experience from long-term service in SCI rehabilitation; 
community-based rehabilitation for people with $\mathrm{SCl}$; vocational rehabilitation practice, research and program evaluation. The collaborative group identified the need for an EIVR service for Queenslanders with recently acquired SCl, an initiative supported by government reports highlighting the need to prioritise vocational rehabilitation for people with severe injuries such as $\mathrm{SCl} .{ }^{31,32}$

\section{Developing the 'Back2Work' Model}

In August 2016 the group was successful in receiving funds from the Queensland Motor Accidents Insurance Commission to develop, implement and evaluate an EIVR program to be integrated within a multidisciplinary hospital-based rehabilitation program for people with recently acquired $\mathrm{SCl}$. The key stakeholders in the developmental process included a team of allied health researchers from Griffith University, vocational rehabilitation specialists from Spinal Life Australia, and staff of the Queensland Spinal Injuries Unit (SIU). The first stage of the development of the new Model, named Back2Work, involved a comprehensive literature review to map the evidence for EIVR in SCl populations. This review highlighted a service gap in vocational rehabilitation after $\mathrm{SCl}$; services typically commence months or years after hospital discharge, missing the opportunity to preserve pre-existing employment. The review also identified additional benefits of early intervention, particularly in its potential to motivate participants and improve adherence to the primary rehabilitation program. ${ }^{33}$

Following the literature review, an empirical survey was conducted of Queenslanders with $\mathrm{SCl}$ sustained in the 3 years prior to the commencement of the Back2Work program. The findings of this mixed-methods survey provided insights from the experiences of people with $\mathrm{SCl}$, including the perception that a lack of 
integrated vocational rehabilitation services within the hospital rehabilitation program was contributing to "lost opportunities, discouragement, and delays in RTW" ${ }^{34(\mathrm{p} 6)}$ The evidence from the literature review and survey informed the team's approach to developing a model for a fully integrated vocational rehabilitation program within the Queensland SIU.

The team used a 'program logic' approach ${ }^{35-37}$ to guide the development of the Back2Work Model. The program logic approach was a critical element in planning the new EIVR program and developing the evaluation strategy by helping to clarify underlying theory; linking evidence and practice to inform processes; making explicit the goals, outcomes and outputs; and guiding program evaluation. ${ }^{36,37} \mathrm{~A}$ program logic inspired diagram ${ }^{35}$ of the Back2Work Model was developed and presented for review to the project's Advisory Board, made up of key industry and consumer stakeholders. This was a cyclical development process with feedback from key stakeholders informing later iterations of the Model, to be presented below.

\section{Key Characteristics of the Back2Work Model}

Following the literature review, baseline survey, collaborative planning meetings, and endorsement of the program logic model by the Advisory Board, some key characteristics were identified as central to the development of the Back2Work (B2W) Model. These were broadly grouped according to the following areas, to be discussed in greater detail below: Guiding Principles; Process; Aims; and Intended Impact. For the purpose of concisely representing the Model's key characteristics, a visual diagram (Figure 1) was developed to assist dissemination. 


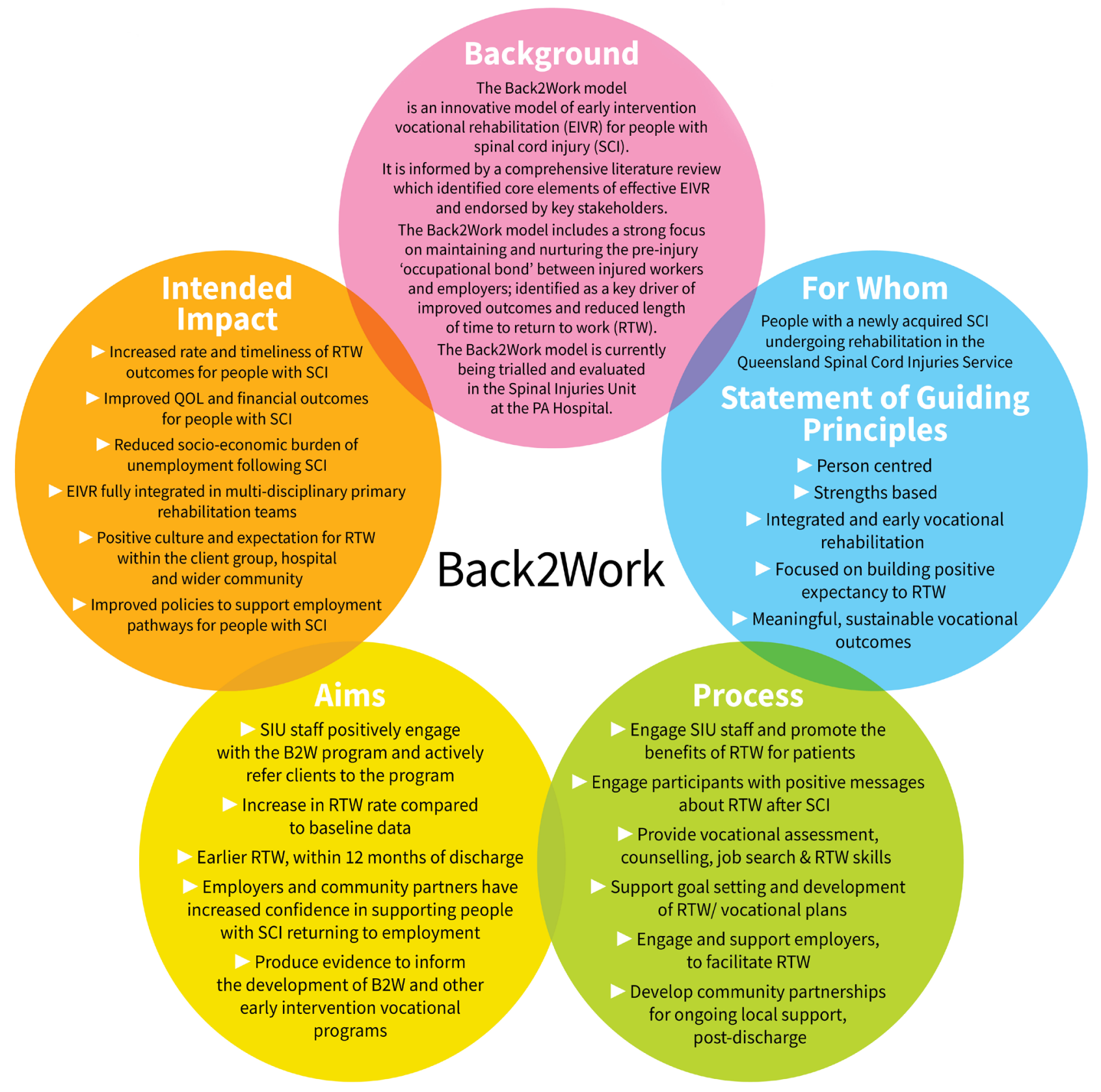

Figure 1. The Back2Work Model of early intervention vocational rehabilitation

The team identified early in the project planning stages that the target

population would be people with recently acquired SCI who had expressed a desire

to engage in vocational rehabilitation. The funding and location of the program meant

that consenting participants needed to be currently undergoing primary rehabilitation 
within the Queensland SIU. The key characteristics of the program were then developed with this target population in mind, acknowledging the trauma that is often associated with $\mathrm{SCl}$ and the individual experiences and needs of people undergoing $\mathrm{SCI}$ rehabilitation. The 'Guiding Principles' of the Back2Work Model reflect these experiences as well as the evidence informing best practice in the field of $\mathrm{SCl}$ vocational rehabilitation. The Back2Work Model therefore prioritises a personcentred ${ }^{38-41}$ and strengths based ${ }^{42-44}$ framework for EIVR that is integrated within the primary SCI rehabilitation phase. ${ }^{8,10,21,29,45,46} \mathrm{~A}$ major focus of Back2Work is on building positive expectancy to RTW ${ }^{19,21,45,47}$ and meaningful, sustainable vocational outcomes for people with SCI. ${ }^{13,21,46,48,49}$

Likewise the evidence supports the operationalisation of the Model's principles through the following key actions of its 'Process'. Firstly, the SIU staff needed to be engaged both early-on and throughout the program's implementation and lifecycle to promote the benefits of RTW for patients, effectively increasing the uptake of service referral among rehabilitation staff. ${ }^{21,46}$ Similarly, these positive messages about RTW after $\mathrm{SCl}$ are echoed in all engagement activities with participants and hospital staff, helping to support hope and confirm the employment benefits and possibilities after injury. ${ }^{8,46}$ In a more practical sense, the Model involves the provision of vocational assessment, vocational counselling, job search, RTW skills training, goal setting support and development of RTW/vocational plans, ${ }^{29,47}$ facilitated by qualified vocational rehabilitation counsellors (VRCs). Along with this 'in-reach' of services to participants, 'out-reach' engagement and support are also provided to employers in facilitating RTW ${ }^{45,50,51}$ and in the development of community partnerships to build capacity for ongoing local support for a person with $\mathrm{SCl}$ post-discharge ${ }^{48}$ particularly in the case of regional and rural services. 
The Model's principles and process are driven by the 'Aims' and key deliverables of the program. These include aims in positively engaging SIU staff to help fully integrate the Back2Work program in the primary rehabilitation team and encourage their referrals to the program; and increasing the rate and timeliness of RTW, in comparison with baseline RTW rates recorded for people with SCI in QLD. Further aims embedded in the Model are the improvement in confidence among employers and community partners in supporting people with $\mathrm{SCl}$ returning to employment; and to produce evidence to inform the further development of Back2Work and other EIVR programs.

The overarching 'Intended Impacts' of the Model are not only to achieve improved RTW outcomes for people with SCI, but other flow-on improvements such as enhanced quality of life and reduced socio-economic burdens associated with unemployment following SCI. Further, it is intended that the Model will help build a more positive culture and expectation for RTW within the SCI population, hospital and wider community, while also supporting broader policy improvements to support employment pathways for people with $\mathrm{SCl}$.

\section{Evaluating the Model's Effectiveness}

The research design for the evaluation of the Model was developed in close collaboration between the researchers and practitioners to ensure a 'good fit' between a methodologically sound design, and the practicality of implementation and evaluation alongside clinical practice. The research was reviewed and approved by the relevant institutional human research ethics committees, to ensure full compliance with the National Statement on Ethical Conduct in Human Research. ${ }^{52}$ 
A prospective longitudinal cohort study is being undertaken, involving the collection of quantitative and qualitative data over a six-year period from program inception (2016-2023). The aims of the evaluation are to investigate the impact of EIVR on the outcomes of people with recently acquired $\mathrm{SCI}$, including employment rate, time taken to return to work, employment retention, job satisfaction, income, and hours worked per week, along with psychosocial adjustment indicators including quality of life and wellbeing. Analysis of service-based data and people's experience of participating in the Back2Work program will help inform the components of vocational rehabilitation likely to be most effective in facilitating vocational outcomes after SCI. Demographic and employment data along with scores on scales such as the Life Satisfaction $9^{53}$ and Kessler $10^{54}$ are collected at intake to the Back2Work program (usually between 4-6 weeks post-injury), at discharge from primary rehabilitation, and 6 monthly thereafter up to a maximum 2 years post-discharge or evaluation close (scheduled for 2023). This follow up data is entered into an SPSS database ${ }^{55}$ and thematic coding is being utilized with the qualitative data, using data analysis software package NVivo ${ }^{56}$ where required. Findings and implications for practice are being published at the conclusion of Phase 1 of the evaluation in $2020^{57}$ and complete project results will be published at the conclusion of Phase 2 in 2023.

\section{Determining Value and Sustainability}

The timing of Back2Work coincided with the introduction of the National Disability Insurance Scheme (NDIS) and the National Injury Insurance Scheme Queensland (NIISQ). One of the indicators of success of these schemes was to be the increased employment participation of people with a disability. ${ }^{58-60}$ While the full evaluation of the Back2Work program will be completed in 2023, initial findings demonstrate the 
value of this program being integrated in the primary rehabilitation space. To date, the phase one evaluation ( $n=79$ as at February 2020) has shown people with recently acquired $\mathrm{SCl}$ are often more willing and interested in vocational exploration and goal setting than traditionally expected. ${ }^{30,57}$ While more detailed results of Back2Work phase one are being published elsewhere, ${ }^{57}$ in presenting the Back2Work Model it is worth summarising some of the key preliminary findings established at the midway point of the evaluation.

At the close of phase one, Back2Work had achieved its initial target of a $30 \%$ or more increase on the baseline employment rate (set at $35 \%$ based on research literature ${ }^{21,33,61}$ ), with a RTW rate of $50 \%$ at 24 months post-discharge from hospital. Further, almost half the participants had returned to vocational activity within 12 months, including having returned to paid employment (43\%) and volunteering (6\%). By far the most common return to work pathway reported in this study was via the pre-injury employer, reinforcing the importance of support for the occupational bond in the RTW journey.

With regard to participant wellbeing, employed participants scored lower on the Kessler10 (K10) psychological distress measure $(M=15.14, S D=3.93)$ than unemployed participants $(M=21.76, S D=7.89)$ at the 6-month follow-up interview $(t(19.38)=-3.17, p=.005)$, reaffirming the role of employment in psychosocial wellbeing. Overall life satisfaction, scored using the LISAT9 was significantly higher for employed $(M=5.00, S D=.67)$ versus unemployed participants $(M=4, S D=$ $1.44)$ at 6 months $(\mathrm{t}(32.94)=2.87, p=.007)$ and 12 months post-discharge $(\mathrm{t}(32)=$ 2.33, $p=.023)$. The embedded satisfaction survey and further qualitative data collected have indicated the very positive overall perception of Back2Work and its 
vocational rehabilitation counsellors in contributing to participants' enhanced sense of wellbeing, optimism and hope for the future.

Back2Work has so far been successful in improving the rate of return to paid employment, promoting timely return to paid employment, and the retention of preinjury employment. Given these outcomes, Back2Work is providing evidence to support the broader integration of vocational rehabilitation in hospital-based multidisciplinary teams, ensuring consistent early access to such services for spinal cord injured people. ${ }^{57}$ It is envisaged that ongoing funding for the program's continuation would naturally sit with the NIISQ, however, this is likely to require further advocacy in order to shift traditional thinking around the timing of vocational rehabilitation and work after major injury. To support this, longitudinal research will be crucial to furthering the momentum in the EIVR field's evidence base. This will require a health economics approach to understanding the costs and benefits of such a service in potentially reducing delays in injury to work resumption timeframes, along with the health and wellbeing improvements associated with returning to work.

\section{Concluding Remarks}

The Back2Work Model is an innovative and evidence-based model of EIVR for people with $\mathrm{SCl}$. The Model was informed by a comprehensive literature review that identified core elements of effective EIVR and endorsed by key stakeholders for implementation in the Queensland Spinal Injuries Unit. Back2Work includes a strong focus on maintaining and nurturing the pre-injury occupational bond between injured workers and employers; identified as a key driver of improved outcomes and reduced length of time to return to work (RTW). The importance of capacity building with employers, regional vocational rehabilitation providers and other support 
services to develop expertise and a culture of expectancy to RTW following SCI, are all emphasised in the approach. The Back2Work Model is showing positive signs of facilitating this positive culture and expectation for RTW; increasing the rate and timeliness of RTW; and improving support for employment related goals for those unable to return to pre-injury employment after SCl. 


\section{References}

1. Dorsett, P., \& Geraghty , T. (2008). Health-related outcomes of people with spinal cord injury—a 10 year longitudinal study. Spinal $\operatorname{Cord}(46), 386-391$.

2. Hoffman, J. M., Bombardier, C. H., Graves, D. E., Kalpakjian, C. Z., \& Krause, J. S. (2011). A longitudinal study of depression from 1 to 5 years after spinal cord injury. Archives of Physical Medicine and Rehabilitation, 92(3), 411-418. https://doi.org/10.1016/j.apmr.2010.10.036

3. Kennedy, P., Lude, P., \& Taylor, N. (2006). Quality of life, social participation, appraisals, and coping post spinal cord injury: a review of four community samples. Spinal Cord, 44, 95-105.

4. Saunders, L. L., Krause, J. S., \& Focht, K. L. (2012). A longitudinal study of depression in survivors of spinal cord injury. Spinal Cord, 50(1), 72-77. https://doi.org/10.1038/sc.2011.83

5. Hess, D., Ripley, D., McKinley, W., \& Tewksbury, M. (2000). Predictors for return to work after spinal cord injury: a 3-year multicenter analysis. Archives of Physical Medicine and Rehabilitation, 81(3), 359-563.

6. World Health Organization \& International Spinal Cord Society. (2014). International Perspectives on Spinal Cord Injury. Albany, United States: World Health Organization.

7. Chan, S. K. K., \& Man, D. W. K. (2005). Barriers to returning to work for people with spinal cord injuires: a focus group study. Work, 25(4), 325-332.

8. Fadyl, J. K., \& McPherson, K. M. (2010). Understanding decisions about work after spinal cord injury. Journal of Occupational Rehabilitation, 20(1), 69-80. https://doi.org/10.1007/s10926-009-9204-1 
9. Ferdiana, A., Post, M. W., Hoekstra, T., van der Woude, L. H., van der Klink, J. J., \& Bültmann, U. (2014). Employment trajectories after spinal cord injury: results from a 5-year prospective cohort study. Archives of Physical Medicine \& Rehabilitation, 95(11), 2040-2046.

https://doi.org/10.1016/j.apmr.2014.04.021

10. Hills, L., \& Cullen, E. (2007). A study into the employment trends of individuals treated at a spinal cord injury centre. International Journal of Therapy \& Rehabilitation, 14(8), 350-355.

11. Anderson, D., Dumont, S., Azzaria, L., Le Bourdais, M., \& Noreau, L. (2007). Determinants of return to work among spinal cord injury patients: a literature review. Journal of Vocational Rehabilitation, 27(1), 57-68.

12. Krause, J. S., Saunders, L. L., \& Acuna, J. (2012). Gainful employment and risk of mortality after spinal cord injury: effects beyond that of demographic, injury and socioeconomic factors. Spinal Cord, 50(10), 784-788.

13. Krause, J. S., Terza, J. V., Saunders, L. L., \& Dismuke, C. E. (2010). Delayed entry into employment after spinal cord injury: factors related to time to first job. Spinal Cord, 48(6), 487-491.

14. Chapin, M. H., \& Holbert, D. (2010). Employment at closure is associated with enhanced quality of life and subjective well-being for persons with spinal cord injuries. Rehabilitation Counseling Bulletin, 54(1), 6-14. https://doi.org/10.1177/0034355210367685

15. Krause, J. S., Kewman, D., DeVivo, M. J., Maynard, F., Coker, J., Roach, M. J., \& Ducharme, S. (1999). Employment after spinal cord injury: an analysis of cases from the model spinal cord injury systems. Archives of Physical Medicine and Rehabilitation, 80(11), 1492-1500. 
16. Murphy, G., Middleton, J., Quirk, R., De Wolf, A., \& Cameron, I. (2011). Predicting employment status at 2 years' postdischarge from spinal cord injury rehabilitation. Rehabilitation Psychology, 56(3), 251-256.

17. Royal Australian College of Physicians and the Australasian Faculty of Occupational and Environmental Medicine (2010). Realising the Health Benefits of Work, a Position Statement. Retrieved from: https://www.racp.edu.au/docs/default-source/advocacy-library/realising-thehealth-benefits-of-work.pdf

18. Bloom, J., Dorsett, P., \& McLennan, V. (2018). Investigating employment following spinal cord injury: outcomes, methods, and population demographics. Disability and Rehabilitation, 1-10. https://doi.org/10.1080/09638288.2018.1467968

19. Dorsett, P. (2010). The importance of hope in coping with severe acquired disability. Australian Social Work, 63 (1), 83-102.

20. Dorsett, P., Geraghty, T., Sinnott, A., \& Acland, R. (2017). Hope, coping and psychosocial adjustment after spinal cord injury. Spinal Cord Series And Cases, 3, 17046. https://doi.org/10.1038/scsandc.2017.46

21. Middleton, J. W., Johnson, D., Murphy, G., Ramakrishnan, K., Savage, N., Harper, R., \& Cameron, I. (2015). Early access to vocational rehabilitation for spinal cord injury inpatients. Journal of Rehabilitation Medicine, 47(7), 626631. https://doi.org/10.2340/16501977-1980

22. Bloom, J., Dorsett, P., \& McLennan, V. (2019). Occupational bonding after spinal cord injury: a review and narrative synthesis. Journal of Vocational Rehabilitation, 50, 109-120. https://doi.org/10.3233/JVR-180992 
23. Safe Work Australia. (2017). The national return to work survey: the role of the employer and workplace. Australia and New Zealand. 2013. Retreived from: https://www.safeworkaustralia.gov.au/doc/return-work-survey-roleemployer-and-workplace-australia-and-new-zealand-2013

24. Holmes, J., Phillips, J., Morris, R., Bedekar, Y., Tyerman, R., \& Radford, K. (2016). Development and evaluation of an early specialised traumatic brain injury vocational rehabilitation training package. British Journal of Occupational Therapy, 79(11), 693-702. https://doi.org/10.1177/0308022616651645

25. Gibran, N. S., Pham, T. N., Mandell, S. P., Carrougher, G. J., \& Brych, S. B. (2017). An intervention bundle to facilitate return to work for burn-injured workers: report from a burn model system investigation. Journal of Burn Care \& Research, 38(1), e70-e78. https://doi.org/10.1097/BCR.0000000000000410

26. Sheppard, D. M., \& Frost, D. (2016). A new vocational rehabilitation service delivery model addressing long-term sickness absence. British Journal of Occupational Therapy, 79(11), 677-681.

27. Hilton, G., Unsworth, C. A., Murphy, G., Browne, M. \& Olver, J. (2017). Longitudinal employment outcomes of an early intervention vocational rehabilitation service for people admitted to rehabilitation with a traumatic spinal cord injury. Spinal Cord, 55(8), 743. https://doi.org/10.1038/sc.2017.24

28. Johnston, D. A., Ramakrishnan, K., Garth, B., Murphy, G., Middleton, J. W., \& Cameron, I. D. (2016). Early access to vocational rehabilitation for inpatients with spinal cord injury: A qualitative study of staff perceptions. Journal of Rehabilitation Medicine, 48(9), 776-780. 
29. Bergmark, L., Westgren, N., \& Asaba, E. (2011). Returning to work after spinal cord injury: exploring young adults' early expectations and experience. Disability and Rehabilitation, 33(25-26), 2553-2558.

30. Dorsett, P., \& McLennan, V. (2017). Back2Work: Optimising vocational rehabilitation outcomes following spinal cord injury. Australian and New Zealand Spinal Cord Society Annual Scientific Meeting 2017, Brisbane Australia, 15-17 November 2017.

31. Productivity Commission. (2011). Disability Care and Support (54). Retrieved from Canberra: https://www.pc.gov.au/inquiries/completed/disabilitysupport/report

32. Queensland Health. (2015). Options Paper - Statewide Spinal Cord Injury Health Service Planning Project. Queensland Government; Brisbane.

33. Bloom, J., Dorsett, P., \& McLennan, V. (2017). Integrated services and early intervention in the vocational rehabilitation of people with spinal cord injuries. Spinal Cord Series And Cases, 3, 16042. https://doi.org/10.1038/scsandc.2016.42

34. Dorsett, P., \& McLennan, V. (2018). Exploring the 'status quo' in vocational rehabilitation and employment outcomes following spinal cord injury. Journal of Vocational Rehabilitation, 50(2), 131-139. http://doi.org/10.3233/JVR180995

35. Holt, I. (2013). Understanding program logic. Retrieved from https://www2.health.vic.gov.au/about/publications/policiesandguidelines/Unde rstanding\%20program\%20logic

36. Kellogg, F. (2004). Using Logic models to bring together planning,evaluation and action: Logic model guide. Retrieved from http://www.wkkf.org/resource- 
directory/resource/2006/02/wk-kellogg-foundation-logic-model-developmentguide

37. Savaya, R., \& Waysman, M. (2005). The logic model: A tool for incorporationg theory in development and evaluation of programs. Administration in Social Work, 29(2), 85-103. https://doi.org/10.1300/J147v29n02_06

38. Bond, G. R. (2004). Supported employment: evidence for an evidence based practice. Psychiatric Rehabilitation Journal, 27(4), 345-359.

39. Lloyd, C. \& King, R. (2012). Implementation of supported employment: what are the implications for clinical services? Journal of Rehabilitation Medicine, 78(1), 25-29.

40. Ottomanelli, L., Barnett, S. D., \& Toscano, R. (2014). Individual placement and support (IPS) in physical rehabilitation and medicine: The VA spinal cord injury experience. Psychiatric Rehabilitation Journal, 37(2), 110-112.

41. Sutton, B. S., Ottomanelli, L., Njoh, E., Barnett, S. D., \& Goetz, L. L. (2015). The impact of social support at home on health-related quality of life among veterans with spinal cord injury participating in a supported employment program. Quality of life research, 24(7), 1741-1747. https://doi.org/10.1007/s11136-014-0912-4

42. Porteous, N., \& Waghorn, G. (2007). Implementing evidence-based employment services in New Zealand for young adults with psychosis: progress during the first five years. The British journal of occupational therapy, 70(12), 251-256.

43. Proyer, R. T., Ruch, W., \& Buschor C, B. (2013). Testing strengths-based interventions: A preliminary study on the effectiveness of a program targeting 
curiosity, gratitude, hope, humor, and zest for enhancing life satisfaction. Journal of Happiness Studies, 14(1), 275-292.

44. Rapp, C. A., Saleebey, D., \& Sullivan, W. P. (2006). The future of strengthsbased social work. Advances in Social Work: Special Issue on the Futures of Social Work, 6(1), 79-90.

45. Krause, J. S., \& Reed, K. S. (2011). Barriers and facilitators to employment after spinal cord injury: underlying dimensions and their relationship to labor force participation. Spinal Cord, 49(2), 285-291.

46. Ottomanelli, L., Barnett, S. D., \& Goetz, L. L. (2014). Effectiveness of supported employment for veterans with spinal cord injury: 2-year results. Archives of Physical Medicine and Rehabilitation, 95(4), 784-790.

47. Lohne, V., \& Severinsson, E. (2006). The power of hope: patient's experiences of hope a year after acute spinal cord injury. Journal of Clinical Nursing, 15, 315-323.

48. Perriam, A. (2008). Wheels in work. Paper presented at the Australia New Zealand Spinal Cord Society Conference (ANZSCoS), Christchurch, NZ.

49. Ramakrishnan, K., Mazlan, M., Julia, P. E., \& Abdul Latif, L. (2011). Return to work after spinal cord injury: factors related to time to first job. Spinal Cord, 49(8), 924-927. http://doi.org/10.1038/sc.2011.16

50. Frieden, L., \& Winnegar, A. J. (2012). Opportunities for research to improve employment for people with spinal cord injuries. Spinal Cord, 50(5), 379-381.

51. Malec, J. F., Buffington, A. L. H., Moessner, A. M., \& Degiorgio, L. (2000). A medical/vocational case coordination system for persons with brain injury: an evaluation of employment outcomes. 81(8), 1007-1015. 
52. National Health and Medical Research Council. (2007). National Statement on Ethical Conduct in Human Research (updated). Canberra: National Health and Medical Research Council.

53. Fugl-Meyer, A. R., Branholm, I. B., \& Fugl-Meye, r. K. S. (1991). Happiness and domain-specific life satisfaction In adult northern Swedes. Clinical Rehabilitation, 5, 25-33.

54. Kessler, R. C., Barker, P. R., Colpe, L. J., Epstein, J. F., Gfroerer, J. C., Hiripi, E., \& Zaslavsky, A. M. (2003). Screening for serious mental illness in the general population. Archives of General Psychiatry, 60(2), 184-189. https://doi.org/10.1001/archpsyc.60.2.184

55. SPSS: IBM Corp, I. C. (2012). IBM SPSS Statistics for Windows, Version 21.0. Armonk, NY: IBM Corp.

56. QSR International. (2012). NVivo 10 [Computer software]: QRSAvailable from http://www.qsrinternational.com

57. Bloom, J. B., McLennan, V., \& Dorsett, P. "Spinal injury is not the end, you can still do the things you have a passion for": results from phase one of an early intervention vocational rehabilitation trial for people with spinal cord injury. In press.

58. Australian Government (2013). National Disability Insurance Scheme Act 2013, https://www.comlaw.gov.au

59. Council of Australian Governments. (2011). National Disability Strategy, https://www.dss.gov.au

60. Queensland Government. (2017). National Injury Insurance Scheme (Queensland) Act 2016. Retreived from: https://www.legislation.qld.gov.au/view/whole/pdf/inforce/current/act-2016-034 
61. Young, A. E., \& Murphy, G. C. (2009). Employment status after spinal cord injury (1992-2005): a review with implications for interpretation, evaluation, further research, and clinical practice. International Journal of Rehabilitation Research, 32(1), 1-11. https://doi.org/10.1097/MRR.0b013e32831c8b19 